\title{
CODE: a practical framework for advancing patient-centred code status discussions
}

\author{
Alec Petersen (D) ,' James A Tulsky, ${ }^{2,3,4}$ Mallika Mendu ${ }^{4,5}$
}

\begin{abstract}
'Internal Medicine Residency Program, Brigham and Women's Hospital, Boston, Massachusetts, USA

${ }^{2}$ Department of Psychosocial Oncology and Palliative Care, Dana Farber Cancer Institute, Boston, Massachusetts, USA ${ }^{3}$ Department of Medicine Division of Palliative Medicine, Brigham and Women's Hosptial, Boston, MA, United States ${ }^{4}$ Harvard Medical School, Boston, Massachusetts, USA ${ }^{5}$ Department of Quality and Safety, Brigham and Women's Hospital, Boston, Massachusetts, USA
\end{abstract}

\section{Correspondence to} Dr Alec Petersen, Internal Medicine Residency Program, Brigham and Women's Hospital, Boston, MA 02115, USA; AWPETERSEN@BWH.HARVARD. EDU

Received 19 December 2019 Revised 27 March 2020

Accepted 16 April 2020 Published Online First 29 April 2020

\section{Check for updates}

(C) Author(s) (or their employer(s)) 2020. No commercial re-use. See rights and permissions. Published by BMJ.

To cite: Petersen A, Tulsky JA, Mendu M. BMJ Qual Saf 2020;29:939-942.

\section{INTRODUCTION}

Every patient admitted to the hospital, scheduled for a procedure or facing a life-limiting illness potentially confronts a decision about cardiopulmonary resuscitation (CPR). Despite their importance and frequency, resuscitation or code status discussions (CSD) are often not included in broader serious illness conversations (SIC) or ignored altogether. ${ }^{1}$ CSDs for patients with serious, life-limiting illness should be incorporated into comprehensive serious illness care delivery, which includes discussions about advance care planning and goals of care at every stage of illness; ideally, for most patients, this will occur early in the disease trajectory. ${ }^{1}$ Yet, even when conversations occur, health systems frequently do not capture code status in an accurate, retrievable, timely and consistent manner. ${ }^{2}$ Failing to understand, document and act on patients' preferences may lead to harm, like other medical errors. Potential outcomes of ineffective CSDs include unwanted CPR or other invasive procedures, and avoidable disability and distress to patients and families. $^{3}$

Barriers to successful SICs and CSDs have been well described. Clinicians leading conversations are often untrained discussing the topic, under time constraints and concerned about conflicting with longitudinal providers. ${ }^{4}$ Patients routinely do not receive clear resuscitation options at the appropriate literacy level and overestimate the chances of successful resuscitation. ${ }^{5}$ Systems lack formal CSD training programmes, poorly implement guidelines and underuse electronic decision support shown to improve CSD documentation. ${ }^{1}$

This viewpoint seeks to define evidence-based high-yield opportunities that address root causes of CSD failures. We have outlined these opportunities in our proposed 'CODE' framework: (1) reduce Choice Complexity leading to poorly understood options; (2) standardise code status Order Entry to reduce errors during care transitions and periprocedurally; (3) guide clinicians away from Delayed Discussions in both inpatient and outpatient settings; (4) eliminate Education Failures that handcuff capable clinicians who lack formalised training. Table 1 illustrates our ideal ' $C O D E$ ' framework for successful CSDs and suggests interventions to address key challenges.

\section{(C) Choice simplification}

The general public understands 'Full Code' as unrestricted CPR with external chest compressions, assisted breathing and shocks. However, few patients are completely informed about the complexities of advanced resuscitation. For example, a subset of patients are accepting CPR but decline intubation, despite evidence that mechanical ventilation is required in over half of patients after cardiopulmonary arrest. Partial Do Not Resuscitate (DNR) orders such as Full Code/Do Not Intubate make little sense medically. Qualitative studies highlight that many patients associate DNR status with less optimal care. ${ }^{5}$ In response, some centres have replaced the DNR with Do Not Attempt Resuscitation (DNAR) to reinforce that CPR is an attempt but not a reliable intervention to restore cardiopulmonary function. Visual aids, such as the Minnesota's Council on Graduate Medical Education's code status patient video, have also been shown to improve patient understanding of the resuscitation procedure. $^{6}$

Ideally, CSDs are part of advanced care planning in patients with chronic 
Table 1 'CODE': a code status improvement framework

\begin{tabular}{|c|c|c|c|}
\hline Phases & Elements of success & Proposed intervention & Evaluation approach/metric \\
\hline $\begin{array}{l}\text { (C) Choice-reduce } \\
\text { complexity }\end{array}$ & $\begin{array}{l}\text { Simplify and reduce the number of } \\
\text { code status options. } \\
\text { Reframe resuscitation as an } \\
\text { attempt at CPR rather than a } \\
\text { procedure likely to restore life. }\end{array}$ & $\begin{array}{l}\text { Replace 'Do Not Resuscitate (DNR)' with 'Do } \\
\text { Not Attempt Resuscitation (DNAR)'. } \\
\text { Simplify code status choices to three options: } \\
\text { DNAR, DNAR/OK to Intubate; and Full Code. } \\
\text { Eliminate inconsistent code status options } \\
\text { including 'Full Code, Do Not Intubate'. }\end{array}$ & $\begin{array}{l}\text { Patient-reported understanding of } \\
\text { resuscitation options. } \\
\text { Percentage of high-risk patients } \\
\text { with resuscitation status as DNAR or } \\
\text { DNAR/OK to Intubate. }\end{array}$ \\
\hline (0) Order-entry support & $\begin{array}{l}\text { Standardised code status order } \\
\text { entry. } \\
\text { Widely understood periprocedural } \\
\text { resuscitation policies. } \\
\text { Code status reconciliation across } \\
\text { clinical encounters. }\end{array}$ & $\begin{array}{l}\text { Develop and implement procedural } \\
\text { resuscitation orders that demand timed Full } \\
\text { Code order expiration for procedural DNR } \\
\text { reversals. } \\
\text { Include guideline-based code status } \\
\text { recommendations to preprocedural checklists. } \\
\text { Implement EHR interruptive alerts to } \\
\text { reconcile code status order discrepancies } \\
\text { AND guide clinicians to perform serious } \\
\text { illness conversation for high-risk patients. }\end{array}$ & $\begin{array}{l}\text { Frequency of code status orders } \\
\text { on hospital admission and } \\
\text { periprocedurally resuscitation } \\
\text { preference (compared with MOLST or } \\
\text { documented SIC). } \\
\text { Frequency of periprocedural } \\
\text { resuscitation status errors. }\end{array}$ \\
\hline (D) Discuss-don't delay & $\begin{array}{l}\text { CSDs occur with a majority of } \\
\text { high-risk patients in the outpatient } \\
\text { setting with longitudinal providers. } \\
\text { Code status confirmed as soon as } \\
\text { possible on hospital admission. }\end{array}$ & $\begin{array}{l}\text { Add code status to EHR dashboards and } \\
\text { implement decision support tools to guide } \\
\text { clinicians to perform and document serious } \\
\text { illness conversations in high-risk patients. } \\
\text { Eliminate 'Presumed' code status as a } \\
\text { durable order on hospital admission. }\end{array}$ & $\begin{array}{l}\text { Frequency of SIC documentation } \\
\text { among high-risk patients. } \\
\text { Frequency of resuscitation status } \\
\text { confirmed on hospital admission. }\end{array}$ \\
\hline $\begin{array}{l}\text { (E) Educate-the } \\
\text { workforce }\end{array}$ & $\begin{array}{l}\text { Adopt a common framework for } \\
\text { serious illness conversations across } \\
\text { the organisation. } \\
\text { Confident and informed } \\
\text { clinicians leading serious illness } \\
\text { and code status discussions. }\end{array}$ & $\begin{array}{l}\text { Institutionalise a common serious illness } \\
\text { conversation (SIC) framework using the } \\
\text { serious illness conversation guide as key tool. } \\
\text { Develop and implement training for all } \\
\text { and preferably VitalTalk simulation-based } \\
\text { instruction for select staff (admitting } \\
\text { physicians, bedside nurses in ICU, surgical } \\
\text { and medical floors). }\end{array}$ & $\begin{array}{l}\text { Percentage of SIC trained staff. } \\
\text { Clinician qualitative measure of } \\
\text { confidence in conducting code status } \\
\text { and SIC. }\end{array}$ \\
\hline
\end{tabular}

CPR, cardiopulmonary resuscitation; CSD, code status discussion; EHR, electronic health record; ICU, intensive care unit; MOLST, Medical Orders for Life-Sustaining Treatment.

illness. However, many CSDs occur unexpectedly after a sudden change in health status or urgent lifethreating illness. Even in patients with prestated preferences, clinicians are expected to review CPR preferences considering new clinical context. Effective CSDs in this situation are challenging given time constraints and varying patient distress and prognostic awareness. Patients and clinicians require clear resuscitation options that overcome ambiguity of the decision-making process. Recommended Summary Plan for Emergency Care and Treatment (ReSPECT), a well-known programme in the UK, encourages emergency planning conversations contextualised by the patient's stated prioritisation of life-sustaining versus comfort-sustaining treatments, and includes a 'yes or no' decision to attempt or not attempt CPR. ${ }^{7}$ We also suggest including the option of 'DNAR but OK to Intubate' which is a common choice for many (eg, reversible airway compromise) to include: (1) DNAR, (2) DNAR but OK to Intubate, and (3) Full Code. Elimination of 'Full Code except OK to Intubate' and other complex orders simplifies the options that are discussed.

\section{(O) Order entry standardisation}

Electronic health records (EHR) represent a key opportunity to capture CSDs and orders without having to search documentation for buried references to patients' preferences. Health systems can implement alerts when code status orders conflict with prior admission code status or preferences stated in SIC documentation. Despite evidence that they significantly increase the rate of conversations, uptake of EHR-based alerts to perform SICs in high-risk patients has been slow. ${ }^{4}$

Code status inconsistencies are pronounced periprocedurally. Despite surgical and anaesthesia guidelines recommending CSDs in patients with code status limitations ensuring goal-concordant care during and after procedures, adherence is inconsistent. One study found that less than half of patients undergoing a palliative procedure had a documented CSD. ${ }^{8}$ Code status orders should be continued between clinical encounters, with the ability to change code status for patients undergoing a procedure. Patient's resuscitation wishes can be complex when facing specific procedural scenarios (eg, intensive care admission or pacemaker implantation), and therefore, procedure-specific communication sheets with nuanced intervention preferences can improve congruence compared with unstructured physician order entry. ${ }^{9}$

Finally, there are clear challenges due to interoperability of order entry standardisation across disparate 
EHRs. Addressing this barrier entails improved state and federal interoperability, as well as increased utilisation of Medical Orders for Life-Sustaining Treatment.

In summary, EHR alerts and standardised order entry, specifically for patients with DNR orders and undergoing a procedure, can facilitate confirmation of code status.

\section{(D) Don't delay: eliminate deferred discussions}

Palliative care experts agree that eliciting patients' goals, and advance care planning including code status, should occur early in the trajectory of illness. ${ }^{10}$ To this end, several effective 'off-the-shelf' discussion tools have been developed. For example, the ReSPECT programme provides standardised advanced care planning documents to facilitate discussion. The steps involved in SIC are outlined in the referenced SIC guide, which include assessing patient understanding, identifying what hopes and worries are most important to the patient, exploring potential trade-offs and making a recommendation aligned with patients' values. These principles apply throughout the disease trajectory and include CSDs. Unfortunately, many face these difficult conversations for the first time in the hospital without the aid of standardised communication tools. Only one in four patients with incurable metastatic cancer were found to have SICs in the outpatient setting. ${ }^{11}$

Delayed SICs in patients have significant consequences: unwanted CPR, increased hospital length of stay and unnecessary health costs. ${ }^{3}$ Of course, inpatient clinicians must revisit patients' goals and preferences at admission and other key transition points. Ideally, these conversations review prior SICs with confirmation of how those goals translate into decisions at the moment, including code status. In some centres, over $50 \%$ of hospitalised patients have a 'presumed' Full Code order. A single-centre study of patients with advanced cancer found that one-half of patients with presumed status had a preference for DNR/DNI. ${ }^{12}$ We advocate for eliminating presumed Full Code, which can cause harm in certain patients. Instead, healthy, low-risk patients should have a Full Code status, and other patients warrant CSDs. Readiness and openness have been identified as key success factors of effective patient engagement in advanced care planning. ${ }^{13}$ We believe that eliminating presumed Full Code orders can facilitate SICs in higher risk groups and foster openness to engage in these conversations.

\section{(E) Educate the workforce}

Studies have demonstrated the importance of highquality SICs and their positive impact on engaging patients in shared decision-making. ${ }^{10}$ Goals of care conversations take on several forms: advanced care planning with longitudinal providers before clinical deterioration, SICs as illness progresses and crisis communication in medical emergencies. The complexity and importance of these conversations has inspired the development of structured communication guides and training. Standardised tools and training are important when considering the most inexperienced clinicians are often leading CSDs. Effective education methods have been described including simulation-based classroom training. ${ }^{14}$ Upfront investment in training appears to be long lasting, with proficiency retained at 1 year. ${ }^{15}$ Broadbased training is needed with prioritisation of hospital admitting clinicians (trainees and attending physicians), intensive care unit nurse staff and specialty physicians who serve as the primary longitudinal care providers for the highest risk patient populations (eg, primary care, cardiology, oncology, geriatrics).

Formally trained clinical staff are more likely to examine patient goals and values and provide a code status recommendation, whereas untrained clinicians are more likely to frame code status as solely patient preference and not share in decision-making. ${ }^{16} \mathrm{We}$ recommend combining communication tools and standardised order entry with a mandated clinician communication skills training programme, such as those offered by the Serious Illness Care Program or VitalTalk. ${ }^{16}$

\section{CONCLUSION}

The CODE framework principles apply across a spectrum of ages and conditions but are most relevant to those with older age ( $>65$ years), life-limiting illness and a 'no' response to the 'surprise question' ('Would I be surprised if this patient died in the next 12 months?'). ${ }^{17}$ Code status preference is frequently ignored, misunderstood or improperly documented, which represents a real patient safety issue resulting in preventable harm. Failures in CSDs can result from choice complexity, order entry errors, delayed discussion and lack of formalised training to conduct these difficult conversations. The CODE framework provides insights and actionable guidance to improve End of Life (EOL) conversations of all types and to reduce code status error.

Funding The authors have not declared a specific grant for this research from any funding agency in the public, commercial or not-for-profit sectors.

Competing interests None declared.

Patient consent for publication Not required.

Provenance and peer review Not commissioned; externally peer reviewed.

Data availability statement All data relevant to the study are included in the article.

ORCID ID

Alec Petersen http://orcid.org/0000-0001-5605-8111 


\section{REFERENCES}

1 Tulsky JA, Beach MC, Butow PN, et al. A research agenda for communication between health care professionals and patients living with serious illness. JAMA Intern Med 2017;177:1361-6.

2 Heyland DK, Barwich D, Pichora D, et al. Failure to engage hospitalized elderly patients and their families in advance care planning. JAMA Intern Med 2013;173:778-87.

3 Brinkman-Stoppelenburg A, Rietjens JAC, van der Heide A. The effects of advance care planning on end-of-life care: a systematic review. Palliat Med 2014;28:1000-25.

4 Haley EM, Meisel D, Gitelman Y, et al. Electronic goals of care alerts: an innovative strategy to promote primary palliative care. J Pain Symptom Manage 2017;53:932-7.

5 Murphy DJ, Burrows D, Santilli S, et al. The influence of the probability of survival on patients' preferences regarding cardiopulmonary resuscitation. N Engl J Med 1994;330:545-9.

6 Merino AM, Greiner R, Hartwig K. A randomized controlled trial of a CPR decision support video for patients admitted to the general medicine service. J Hosp Med 2017;12:700-4.

7 For up to date information about decision-making in a time of COVID-19, please visit our COVID-19 resource library. Available: https://www.resus.org.uk/respect/ [Accessed 13 Mar 2020].

8 Urman RD, Lilley EJ, Changala M, et al. A pilot study to evaluate compliance with guidelines for Preprocedural reconsideration of code status limitations. J Palliat Med 2018;21:1152-6.

9 Heffner JE, Barbieri C, Fracica P, et al. Communicating do-notresuscitate orders with a computer-based system. Arch Intern Med 1998;158:1090-5.
10 Bernacki RE, Block SD. American College of physicians high value care task $\mathrm{f}$. communication about serious illness care goals: a review and synthesis of best practices. JAMA Intern Med 2014;174:1994-2003.

11 Temel JS, Greer JA, Admane S, et al. Code status documentation in the outpatient electronic medical records of patients with metastatic cancer. J Gen Intern Med 2010;25:150-3.

12 El-Jawahri A, Lau-Min K, Nipp RD, et al. Processes of code status transitions in hospitalized patients with advanced cancer. Cancer 2017;123:4895-902.

13 Zwakman M, Jabbarian LJ, van Delden J, et al. Advance care planning: a systematic review about experiences of patients with a life-threatening or life-limiting illness. Palliat Med 2018;32:1305-21.

14 Paladino J, Kilpatrick L, O'Connor N, et al. Training clinicians in serious illness communication using a structured guide: evaluation of a training program in three health systems. $J$ Palliat Med 2020;23:337-45.

15 Fallowfield L, Jenkins V, Farewell V, et al. Enduring impact of communication skills training: results of a 12-month followup. Br J Cancer 2003;89:1445-9.

16 Paladino J, Bernacki R, Neville BA, et al. Evaluating an intervention to improve communication between oncology clinicians and patients with life-limiting cancer: a cluster randomized clinical trial of the serious illness care program. JAMA Oncol 2019;5:801-9.

17 Mudge AM, Douglas C, Sansome X, et al. Risk of 12-month mortality among hospital inpatients using the surprise question and SPICT criteria: a prospective study. BMJ Support Palliat Care 2018;8:213-20. 